\title{
PEROXIDASE (POD) E POLIFENOLOXIDASE (PPO) EM POLPA DE GOIABA (Psidium guajava R.) ${ }^{1}$
}

\author{
Caroline Lima ZANATTA², Marta Fernanda ZOTARELLI², Edmar CLEMENTE ${ }^{2, *}$
}

\section{RESUMO}

A peroxidase E.C. 1.11.1.7 (POD) e a polifenoloxidase E.C. 1.10.3.1 (PPO) foram extraídas da polpa de goiaba. Os extratos foram preparados utilizando-se a polpa da goiaba e solução tampão fosfato de sódio $100 \mathrm{mM}$ com pH variando de 6,0 a 7,0 em intervalos de 0,1 . Foi determinada a atividade enzimática da peroxidase e da polifenoloxidase desses extratos, a fim de se observar o melhor pH para a extração de cada enzima. O pH 6,3 foi considerado o melhor para a extração da POD da polpa de goiaba, enquanto que para PPO, o $\mathrm{pH}$ foi 6,8 . Os extratos brutos de POD e PPO foram submetidos a temperaturas de $60{ }^{\circ} \mathrm{C}, 65{ }^{\circ} \mathrm{C}, 70^{\circ} \mathrm{C}, 75^{\circ} \mathrm{C}$ e $80{ }^{\circ} \mathrm{C}$ por um período de 0 a $10 \mathrm{~min}$. Os resultados demonstraram um decréscimo da atividade enzimática nos extratos com o aumento da temperatura e do tempo. No entanto, a total inativação não foi atingida o que sugere a presença de isoenzimas termoresistentes.

Palavras-chave: peroxidase, polifenoloxidase, atividade enzimática, goiaba, polpa.

\section{SUMMARY}

PEROXIDASE (POD) AND POLYPHENOLOXIDASE (PPO) IN GUAVA (Psidium Guajava R.) PULP. Peroxidase E.C. 1.11.1.7 (POD) and polyphenoloxidase E.C.1.10.3.1 (PPO) were extracted from guava pulp. The extracts were prepared using guava pulp and a sodium phosphate buffer $100 \mathrm{mM}$ with a pH varying from 6.0 to 7.0 in intervals of 0.1 . This was done in order to observe the best pH for the extraction of each enzyme. The $\mathrm{pH}$ of 6.3 was considered the best in terms of extracting POD from guava pulp while the pH was 6.8 for the PPO extraction. The POD and PPO extracts of guava pulp were exposed to temperatures of $60{ }^{\circ} \mathrm{C}, 65^{\circ} \mathrm{C}, 70{ }^{\circ} \mathrm{C}, 75^{\circ} \mathrm{C}$ and $80{ }^{\circ} \mathrm{C}$ in a period between 0 to $10 \mathrm{~min}$. The result showed a decrease in the enzymatic activity due to the increase of the temperature and time. However, total inactivation was not achieved which suggests the presence of thermo resistant isoenzymes.

Keywords: peroxidase, polyphenoloxidase, enzymatic activity, guava, pulp.

\section{1- INTRODUÇÃO}

A goiaba é uma fruta considerada muito importante dentro do contexto da fruticultura brasileira, encontrandose em expansão. Embora a sua produção no Brasil represente aproximadamente 280 mil toneladas, concentradas nos meses de fevereiro e março, a comercialização da fruta ocorre o ano todo. O aumento no consumo está associado à grande divulgação das qualidades nutricionais da fruta. Por se tratar de uma fruta altamente perecível, o conhecimento de sua fisiologia pós-colheita é fundamental para o emprego adequado de tecnologias, visando aumentar o período de conservação. Após a colheita de frutas e hortaliças inicia-se uma série de processos degradativos que aceleram a senescência, causando perdas de grande parte da produção. Diversas dessas perdas podem ser atribuídas à ação de enzimas durante a pós-colheita.

A polifenoloxidase (PPO; EC 1.10.3.1) e a peroxidase (POD; EC 1.11.1.7) estão presentes em um grande grupo de frutas e vegetais [14]. Elas fazem parte de um grande número de enzimas conhecidas como oxiredutases,

\footnotetext{
${ }^{1}$ Recebido para publicação em 26/12/2005. Aceito para publicação em 6/7/2006 (001656)

${ }^{2}$ Laboratório de Bioquímica de Alimentos (DQI),

Universidade Estadual de Maringá,

Av. Colombo, 5790, CEP 87020-900, Maringá (PR), Brasil

E-mail:eclemente@uem.br

* A quem a correspondência deve ser enviada
}

podendo promover uma variedade de reações, principalmente a peroxidase $[3,4]$. A investigação desse grupo de enzima tem sido de grande importância para a tecnologia de alimentos, uma vez que a continuidade da atividade enzimática pode ocasionar mudança na cor, variações de aroma, alterações no teor de vitaminas e até modificações na textura $[5,7,12,9]$.

Desde a sua descoberta no século passado, as enzimas PPO e POD têm sido objeto de extensas pesquisas científicas. Com isso, considerável importância tem sido acumulada sobre as propriedades moleculares e catalíticas, como também sobre o papel que estas jogam no ciclo da vida das plantas e em alguns casos; na tecnologia de alimentos [14, 10, 11].

A peroxidase é uma enzima resistente a elevadas temperaturas e sua inativação tem sido freqüentemente usada como índice da efetividade do branqueamento, tratamento térmico aplicado em alimentos para inibir a ação das enzimas. A perda da sua atividade enzimática num produto branqueado indica uma perda correspondente da atividade para outras enzimas de deterioração [6]. Em enzimas, o objetivo do processamento térmico é a sua inativação, já em nutrientes e fatores de qualidade, é a retenção máxima das características organolépticas.

Este trabalho objetivou avaliar a atividade da polifenoloxidase e da peroxidase em polpa de goiaba e estudar o comportamento de suas atividades enzimáticas frente ao tratamento térmico. 


\section{2 - MATERIAL E MÉTODOS}

As goiabas estudadas pertencem à variedade Paluma, derivada da variedade Rubi-Supreme, a partir de sementes de polinização aberta. Os frutos maduros foram colhidos no Sítio Centenário, na cidade de Mandaguaçu - PR.

Após a colheita, os frutos foram levados para o Laboratório de Bioquímica de Alimentos da Universidade Estadual de Maringá, onde foram selecionados e sanitizados. Todos os reagentes utilizados foram de grau analítico, obtidos da Sigma e/ou Merck.

\section{1 - Preparação dos extratos enzimáticos em diferentes pHs}

Os frutos foram higienizados com água destilada, em seguida foram retiradas a casca e as sementes. Pesaram-se $50 \mathrm{~g}$ de polpa, as quais foram homogeneizadas por $2 \mathrm{~min}$, utilizando-se um liquidificador, com $100 \mathrm{~mL}$ de solução tampão fosfato de sódio $100 \mathrm{mM}$ em diferentes pHs $(6,0$; $6,1 ; 6,2 ; 6,3 ; 6,4 ; 6,5 ; 6,6 ; 6,7 ; 6,8 ; 6,9$ e 7,0$)$.

As misturas resultantes foram filtradas em tecido de algodão e o filtrado obtido, recolhido em béquer em banho de gelo. Os filtrados foram centrifugados $(12.000 \mathrm{rpm}$, a $4{ }^{\circ} \mathrm{C}$ por $20 \mathrm{~min}$ ); os sobrenadantes, armazenados a $-18^{\circ} \mathrm{C}$; e os resíduos, descartados.

\section{2 - Preparação dos extratos de peroxidase e polifenoloxidase}

Após a definição do melhor pH de extração, novos extratos de goiaba foram preparados pesando-se $50 \mathrm{~g}$ de polpa, que foi homogeneizada com $100 \mathrm{~mL}$ de tampão fosfato de sódio $100 \mathrm{mM} \mathrm{em} \mathrm{pH} \mathrm{6,3} \mathrm{para} \mathrm{a} \mathrm{peroxidase} \mathrm{e} \mathrm{pH} 6,8$ para a polifenoloxidase. Foram adicionados, antes da homogeneização, polivinilpirrolidone (PVPP) 5\% e cloreto de cálcio, para evitar a ação de fenóis e da pectina. A solução foi filtrada em tecido de algodão e o filtrado foi recolhido em béquer em banho de gelo. $O$ filtrado foi centrifugado a $12.000 \mathrm{rpm}$, a $4{ }^{\circ} \mathrm{C}$ por $20 \mathrm{~min}$. O sobrenadante foi congelado a $-18{ }^{\circ} \mathrm{C}$, o resíduo da solução de $\mathrm{pH}$ 6,8 foi descartado e o da solução de pH 6,3 foi tratado com solução 1,0 M de cloreto de sódio em tampão (fosfato de sódio $100 \mathrm{mM} \mathrm{e} \mathrm{pH} \mathrm{6,3),} \mathrm{para}$ extração da peroxidase ionicamente ligada, e novamente centrifugado.Os resíduos foram estocados a $-18^{\circ} \mathrm{C}$.

\section{3 - Atividade enzimática da peroxidase e da polifenoloxidase}

A atividade da POD foi determinada pelo método descrito por CLEMENTE [4]. Uma unidade de atividade de POD foi definida com o aumento de uma unidade de absorbância por minuto/mL. A atividade da PPO foi determinada de acordo com o método descrito por FUJITA [8] modificado: misturou-se $0,5 \mathrm{~mL}$ do substrato de PPO com $0,8 \mathrm{~mL}$ de tampão fosfato de sódio $100 \mathrm{mM}, \mathrm{pH}$ 6,8, e 0,05 mL de solução de catecol $10 \mathrm{mM}$; em seguida, a mistura foi incubada por $30 \mathrm{~min}$ a $30{ }^{\circ} \mathrm{C}$ em banho-maria. Após o período de incubação, adicio- nou-se $0,8 \mathrm{~mL}$ de solução de ácido perclórico $2 \mathrm{M}$ e os tubos foram imersos em banho de gelo. A atividade foi determinada $(\lambda=395 \mathrm{~nm})$. A unidade de atividade de PPO foi definida com o aumento de uma unidade de absorbância por minuto/mL.

\section{4 - Tratamento térmico}

Os extratos brutos de POD e PPO da goiaba foram submetidos ao tratamento térmico em cinco diferentes temperaturas: $60^{\circ} \mathrm{C}, 65^{\circ} \mathrm{C}, 70^{\circ} \mathrm{C}, 75^{\circ} \mathrm{C}$ e $80^{\circ} \mathrm{C}$ por até $10 \mathrm{~min}$, de acordo com o método descrito por VALDERRAMA \& CLEMENTE [13].

\section{3 - RESULTADOS E DISCUSSÃO}

A determinação da atividade enzimática dos extratos brutos de goiaba para PPO e POD em diferentes valores de $\mathrm{pH}$ permitiu encontrar o $\mathrm{pH}$ ótimo de extração destas enzimas no fruto. A relação entre $\mathrm{pH}$ e a atividade enzimática dos extratos são mostradas nas Figuras $1 a$ e $1 b$.
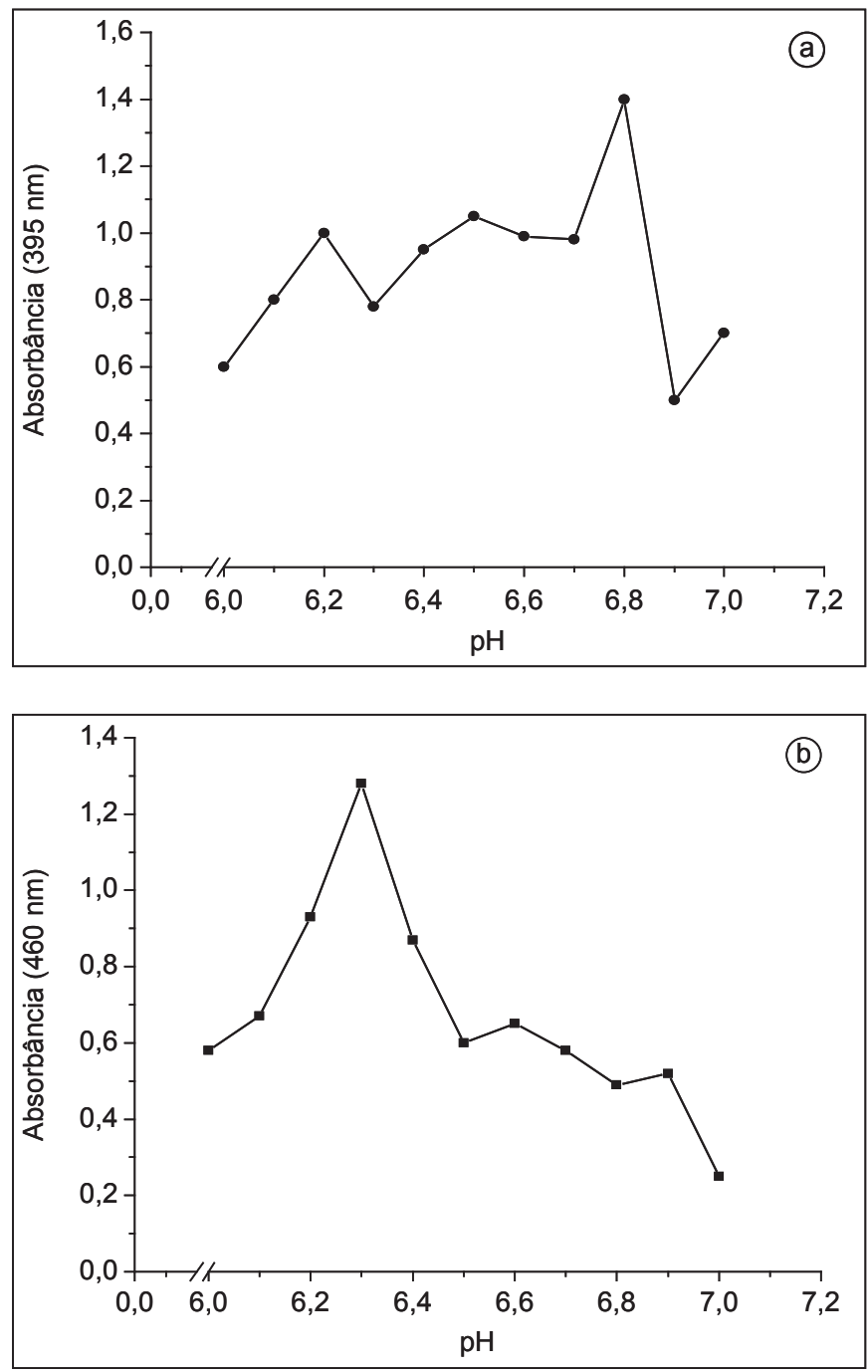

FIGURA 1 - a) Atividade enzimática da PPO; e b) Atividade enzimática da POD, em extratos da polpa de goiaba preparados em diferentes pHs. 
Os resultados mostraram que, para a POD, a máxima atividade enzimática ocorreu com o extrato preparado em pH 6,3. Para a PPO, o extrato preparado em $\mathrm{pH}$ 6,8 permitiu a maior atividade enzimática.

Após a definição do melhor pH de extração, novos extratos enzimáticos de peroxidase solúvel (PSG) e ionicamente ligada (PIG) da polpa de goiaba foram preparados em $\mathrm{pH}$ 6,3, seguindo-se o método já descrito.

Na Tabela 1, podem ser observados os valores encontrados para a atividade da peroxidase fração solúvel (PSG) e peroxidase ionicamente ligada (PIG), bem como a atividade da polifenoloxidase (PPO) em polpa de goiaba.

TABELA 1 - Atividade enzimática da POD e PPO em polpa de goiaba $(n=3)$.

\begin{tabular}{ccc}
\hline Extratos & $\Delta$ DO/min.mL & $\delta$ \\
\hline PSG & 1,15 & $\pm 0,05$ \\
PIG & 2,90 & $\pm 0,02$ \\
PPO & 1,51 & $\pm 0,02$ \\
\hline
\end{tabular}

PSG - peroxidase solúvel de polpa de goiaba; PIG - peroxidase ionicamente ligada de polpa de goiaba; $\mathrm{PPO}$ - polifenoloxidase de polpa de goiaba; $\mathrm{n}=$ número de repetições; e $\delta=$ desvio-padrão

O tratamento térmico aplicado para a peroxidase ionicamente ligada (PIG) apresentou valores de atividade enzimática inicial superior à fração solúvel. No entanto, após o tratamento térmico, observou-se um acentuado decréscimo da atividade da peroxidase da fração ionicamente ligada (PIG) (Figura 2), quando comparada à atividade da fração solúvel (PSG) que também foi submetida aos mesmos tratamentos térmicos. Estas diferenças podem ser devido à presença de isoenzimas que apresentam termo estabilidade diferente. Observação esta semelhante à obtida por BERBICZ \& CLEMENTE [2].

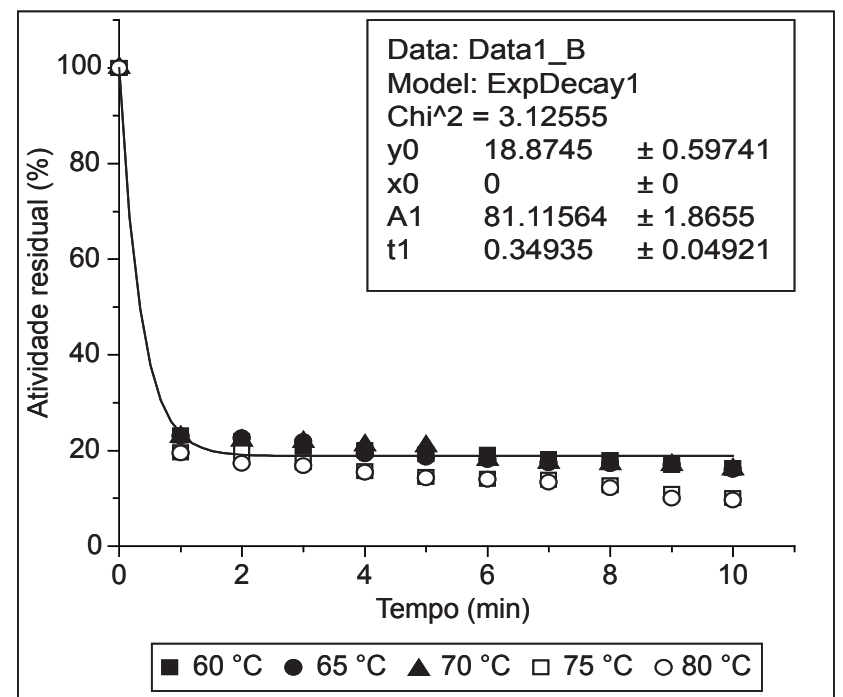

FIGURA 2 - Efeito do tratamento térmico na fração da peroxidase ionicamente ligada (PIG) extraída da polpa de goiaba.
Na Figura 2, pode-se observar uma perda em torno $80 \%$ da atividade inicial no primeiro minuto do tratamento, independente da temperatura. No entanto, o aumento da temperatura e do tempo não influenciou de forma a inativar as isoenzimas presentes na fração ionicamente ligada, mantendo uma atividade residual de aproximadamente $20 \%$.

Os resultados dos tratamentos térmicos da fração solúvel da peroxidase (PSG) podem ser observados na Figura 3, e a variação da atividade enzimática da PPO na Figura 4.

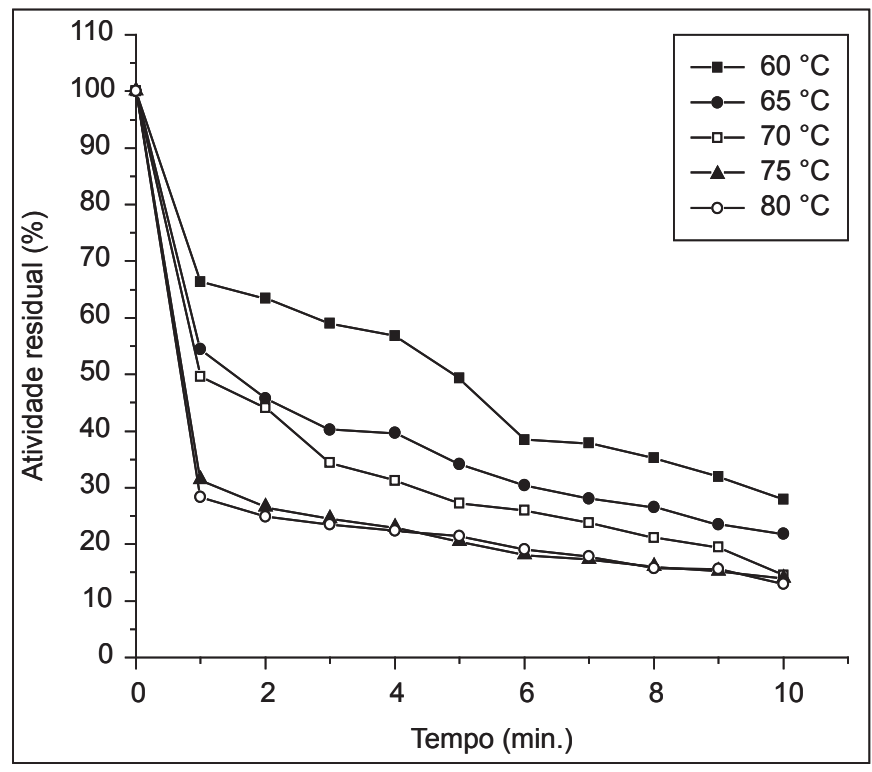

FIGURA 3 - Efeito do tratamento térmico na fração solúvel da peroxidase (PSG) da polpa de goiaba.

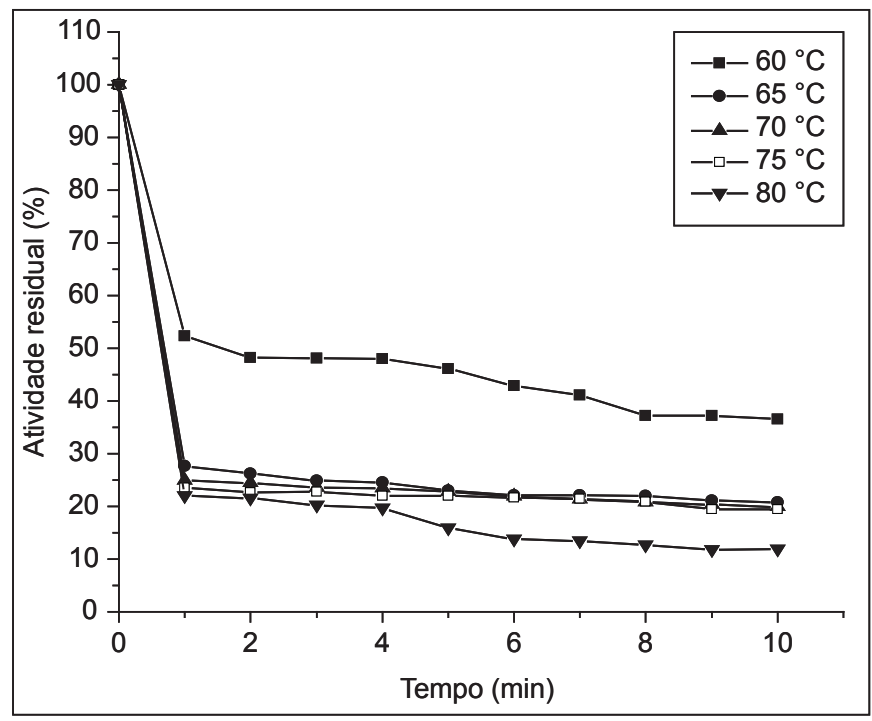

FIGURA 4 - Efeito do tratamento térmico na PPO da polpa de goiaba. 
Durante o tratamento térmico dos extratos enzimáticos, foi observado um decréscimo quase que contínuo da atividade de POD e PPO em todas as temperaturas, tendo, porém, um maior decréscimo nos primeiros minutos. Os resultados encontrados são semelhantes aos observados por VALDERRAMA, MARAGONI \& CLEMENTE [12]. Os tratamentos térmicos aplicados neste trabalho não foram capazes de inativar totalmente estas enzimas, estando de acordo com ALVIM \& CLEMENTE [1], que atribuem às isoenzimas termoestáveis as possíveis causas pela dificuldade na inativação completa das enzimas estudadas.

Novos estudos, no sentido de isolar e caracterizar estas enzimas, devem ser realizados para melhor entendimento do comportamento enzimático frente ao tratamento térmico.

\section{4 - CONCLUSÕES}

Entre os pHs avaliados, o pH 6,3 foi considerado o melhor para a extração da POD presente na polpa de goiaba e o pH 6,8, para a PPO.

A enzima ionicamente ligada apresentou uma atividade superior ao da peroxidase solúvel.

$\mathrm{O}$ aumento da temperatura e do tempo influenciou a atividade das enzimas, embora não tenham sido suficientes para a inativação total da PPO e POD.

\section{5 - REFERÊNCIAS BIBLIOGRÁFICAS}

[1] ALVIM, K.; CLEMENTE, E. Estudo da termoestabilidade de peroxidase extraídas da polpa e casca de mexerica (Citrus deliciosa). Acta Scientiarum, v. 2, n. 3, p. 201204, 1998.

[2] BERBICZ, F.; CLEMENTE, E. Avaliação da termoestabilidade e da regeneração da atividade da peroxidase extraída de laranja (Citrus ssp). Acta Scientiarum, v. 23, n. 5, p. 1239-1242, 2001.

[3] CLEMENTE, E. The characterization of isoperoxidases from orange. England, 1993, 202 p. Tese PhD in Food Science, Leeds, England, University of Leeds - Procter Food Science.

[4] CLEMENTE, E. Purification and thermo stability of isoperoxidase from oranges. Phytochemistry, v. 49, n. 1, p. 29-36, 1998.
[5] Clemente, E.; PAStore, G. M. Peroxidase and polyphenoloxidase, the importance for food technology. Boletim da Sociedade Brasileira de Ciências e Tecnologia de Alimentos, v. 32, n. 2, p. 167-171, 1998.

[6] ESKIN, N. A. M. Biochemistry of Foods. 2a edição. Academic Press, Canadá Serie, p. 506-507, 1990.

[7] EVANGELISTA, J. Tecnologia de Alimentos. $3^{\text {a }}$ edição. São Paulo: Atheneu, 2001.

[8] FUJITA, S.; SAARI, N.; MAEGAWA, M.; TETSUKA, T.; HAYASHI, N. and TONO, T. Purification and properties polyphenol oxidase from cabbage (Brassica oleracea L.). Journal Agriculture Food Chemistry, v. 43, n. 5, p. 1138-1142, 1995.

[9] LAURENTE, C.; CLEMENTE, E. Avaliação da atividade da peroxidase em carambola (Oxalidacia averrhoa) em diferentes estádios de maturação. Acta Scientiarum, v. 27 , n. 1, p. 159-163, 2005.

[10] ROBINSON, D. S., Food Biochemistry \& Nutricional Value, Longman Scientific \& Techhinical, Essex, 1987.

[11] ROBINSON, D. S., Peroxidases and Catalases in Food. In: ROBINSON, D. S.; ESKIN, N. A. M. (Ed) Oxidative Enzymes in Food. Elsevier Science Publishers LTD, Essex, 1991. p. 1-47.

[12] VALDERRAMA, P.; MARANGONI, F., CLEMENTE, E. Efeito do tratamento térmico sobre a atividade de peroxidase (POD) e polifenoloxidase em maça (Mallus comunis). Ciência Tecnologia de Alimentos, v. 21 , n. 3, p. 321-325, 2001.

[13] VALDERRAMA, P.; CLEMENTE, E. Isolation and thermostability of peroxidase isoenzymes from apple cultivares Gala and Fuji. Food Chemistry, v. 87, p. 601-606, 2004.

[14] VAMOS-VIGYAZO, L. Polyfhenoloxidase and peroxidase in fruits and vegetables. CRC Crit Ver. Food Science Nutrition. Boca Raton/USA, v. 49, p. 127, 1981.

\section{6 - AGRADECIMENTOS}

Ao CNPq, pela concessão da bolsa de iniciação científica PIBIC/UEM, e ao Sítio Centenário, da cidade de Mandaguaçu - PR, pelo fornecimento de amostras para a realização do trabalho. 